\title{
Reward schedule effects at a relatively long intertrial interval '
}

\section{E. J. CAPALDI AND ROBERT MINKOFF UNIVERSITY OF TEXAS}

Employing a minimum 20 min intertrial interval (ITI) and extended acquisition training, it was found that a single alternation schedule of partial reward produced less resistance to extinction than an irregular schedule. These results support the sequential hypothesis and appear incompatible with the frustration hypothesis.

The sequential hypothesis (Capaldi, 1966) expects a single alternating (SA) schedule of partial reward to produce less resistance to extinction ( $R$ to $E$ ) than a $50 \%$ irregular (I) schedule following considerable acquisition training. The frustration hypothesis expects no difference between SA and I. Surridge \& Amsel (1966) employing a $24 \mathrm{~h}$ ITI and considerable acquisition training, reported that in extinction SA ran significantly slower than $I$ in all sections of the runway. They indicate that the extinction differences might have been due to terminal acquisition differences. By the end of acquisition training SA ran slower than I in the goal section of the alley. It was decided to compare $R$ to $E$ following SA and I training under a relative long ITI (minimum of $20 \mathrm{~min}$ ).

Method

The 18 male naive rats purchased from the Holtzman Co., Madison, Wisconsin, were about 90 days old at the start of the experiment. The $12 \mathrm{~g}$ per day deprivation schedule was begun 12 days prior to the 21 day experimental phase, handling beginning on Day 9. The straight-alley runway $(69-1 / 4$ in. long, 4 in. wide) has been described in greater detall elsewhere (Capaldi \& Lynch, 1966). The nine Ss of Group SA received a single alternation schedule on each of the 16 days of acquisition, Trial 1 of each day always being rewarded (wet mash), Trial 10, the last trial of each day, always being nonrewarded (empty, identical appearIng goal cup). Group 1 was given a different irregular schedule each day of five rewards and five nonrewards. Trial 1 and Trial 10 of each day were always rewarded. Number of nonrewards in succession in the I schedule were either $1,2,3$, or 4 , each of these " $\mathrm{N}$-lengths" occurring eight times over the 16 day acquisition phase. Each 10 trial irregular schedule contained two transitions from a rewarded trial to a rewarded trial. By way of example one of the I schedules employed was $R, N, R, R, N, N, N, N, R, R$. The 18 rats were run in rotation such that on a given day an SA rat followed an SA rat and on the following day the SA rat followed an I rat. This was accomplished by putting the rats in a rack in the order $S A, I, I, S A$, etc. On Day 1 the animals were run left to right, on Day 2 right to left, and so on. The ITI was a minimum of $20 \mathrm{~min}$ (range 20 to $50 \mathrm{~min}$ ). Confinement on all rewarded and nonrewarded trials was $20 \mathrm{sec}$. The $20 \mathrm{sec}$ value was chosen to minimize the possibility of pattern learning in Group SA (Capaldi \& Lynch, 1966). If patterning were prevented, Group SA would not run slower than Group I in terminal acquisition, and thus a rate transformation on the extinction scores could be avoided. There were five days of extinction, also at 10 trials per day. All conditions were the same in extinction except that Ss were never rewarded.

Results

Figure 1 shows running speed (1/time) in Groups $\mathrm{SA}$ and I along the total length of the alley on each day of acquisition and extinction. Section results in acquisition were quite similar to those shown in Fig. 1 for total speed. In extinction, however, start section differences were bigger than those shown for total speed, run section differences were about the same and goal section differences were somewhat smaller. On the last day of acquisition training, differences in total speed between the groups were not significant $(F<1)$. An analysis over the 50 trials of extinction shown in Fig. 1 indicated that the day difference was significant ( $F=58.48$, df $=4 / 64, p<.001)$, i,e., the groups extinguished. While the group difference was not significant ( $F=2.45$, df $=1 / 16$ ), the groups by days interaction was highly significant $(F=4.53, \mathrm{df}=4 / 64, \mathrm{p}<.01$ ), indicating that Group SA extinguished at a faster rate over days than Group I. An analysis performed on the last day of extinction indicated that the difference between Group SA and Group I was significant at well

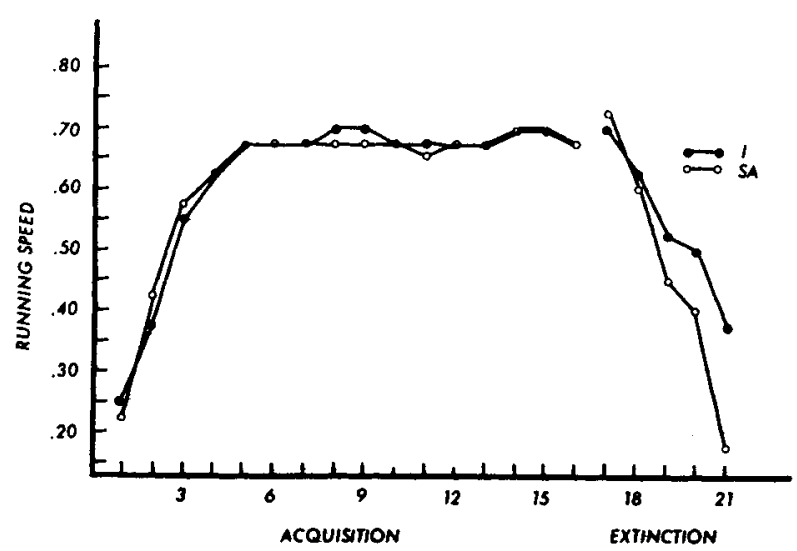

Fig. 1. Mean total speed in Group 1 and Group SA on each of the 16 days of acquisition and the five days of extinction. 
beyond the .05 level $(F=6.79$, df $=1 / 16)$. From the present results and those reported by Surridge and Amsel it appears that differences between Groups SA and I require a greater number of trials to develop under spaced trials than under massed trials and that a danger exists in terminating extinction too soon under spaced trials.

\section{Discussion}

Under massed trials (15-30 sec) SA has typically produced less $R$ to $E$ than I (e.g., Tyler, Wortz, \& Bitterman, 1953). This effect occurred here when ITI was extended to a minimum of $20 \mathrm{~min}$. Spence (1960) suggests two alternative possibilities concerning the growth of $\mathrm{rg}_{\mathrm{g}}$ under partial reward (see p. 100). Under either alternative, the frustration hypothesis must predict that Groups SA and I will (a) have the same $r_{g}$, (b) experience the same number and intensity of frustrative nonrewards, (c) show equal $R$ to $E$ under either massed or spaced trials.

Let us refer to differences obtained between schedules such as SA and I, which contain the same number of rewards and nonrewards, as reward schedule effects. Surridge and Amsel apparently assumed that reward schedule effects, which have been shown many times to occur under massed trials, would occur only for massed trials and not for spaced trials. This would support their contention that massed trial reward schedule effects are artifactual, and therefore the frustration hypothesis is under no obligation to explain them. The present results suggest, of course, that reward schedule effects occur under spaced trials.

Tests of the proposition that reward schedule effects may occur at even longer ITIs, e.g., $24 \mathrm{~h}$, could profitably employ a more appropriate I group than Surridge and Amsel. In acquisition, their I group received a maximum of only two consecutive nonrewards (vs four here and three in previous massed trial studies) thus differing as minimally as possible from Group SA. The less the differences of this sort, of course, the less the expected differences in $R$ to $E$ (Capaldi, 1966).

\section{References}

CAPALDI, E. J. Partial reinforcement: A hypothesis of sequential effects. Psychol Rev., 1966, 73, 459-477.

CAPALDI, E. J., \& LYNCH, D. Patterning at 24hour ITI: Resolution of a discrepancy more apparent than real. Psychon. Sci, 1966, 6, 229230.

SPENCE, K. W. Behavior theory and learning. Englewood Cliffs: Prentice Hall, 1960.

SURRIDGE, E. T., \& AMSEL, A. Acquisition and extinction under single alternation and random partial reinforcement conditions with a 24-hour intertrial interval. J. exp. Psychol., 1966, 72, 361-368.

TYLER, D. W., WORTZ, E. C., \& BITTERMAN, M. E. The effect of random and alternating partial reinforcement on resistance to extinction in the rat. Amer. J. Psychol, 1953, 66, 57-65.

Note

1. This research was supported in part by National Institute of Child and Health Development Research Grant HD 00949-04 to the first author. 